\title{
Mastery Goal, Value, and Self-concept: What do they predict?
}

\author{
Alexander S. Yeung, Rhonda G. Craven, and Gurvinder Kaur
}

\section{Acknowledgement}

The research was funded by the Australian Research Council.

\begin{abstract}
Background

Students' motivation is known to influence academic outcomes. However there is a paucity of research showing the relative influences of motivational factors on short-term and long-term outcomes.

Purpose

The study investigates the relative influences of motivational factors - mastery goal orientation, value of schooling, and academic self-concepts (perceived competence in and affect to schoolwork) on four outcomes - rule acceptance, identity, general self-efficacy and achievement.

Sample

Students in grades 3 to 6 from six primary schools in the Sydney were surveyed $(N=979)$. The ages of the participants varied from 8 to 13 years $(M=9.78)$.

Design and methods

Students completed a questionnaire and literacy and numeracy achievement tests. Structural equation modeling was used to examine the paths from four predictors to four outcomes.

Results

Whereas all four predictors were positively associated with all four outcomes, students' mastery goal had stronger positive influences on self-efficacy and identity. Value, perceived competence, and affect were found to influence outcomes in different ways - positive influences were found for value on achievement, rule-acceptance, and identity; for perceived competence on achievement and efficacy; and for affect on ruleacceptance and identity.

Conclusion

Mastery goal had stronger influences on long-term outcomes while other predictors are stronger for shortterm outcomes. To facilitate short-term and long-term outcomes, all four motivational factors need attention.
\end{abstract}

Keywords: Motivation; self-concept; primary education; structural equation modelling; value; educational psychology 


\section{Introduction}

Research has postulated that self-concept and motivation may significantly influence learning (Marsh and Scalas 2010; Craven and Yeung 2008). Much of the related literature has focused on either motivation or self-concept and on short-term educational outcomes. Given the increasing popularity of considering broader educational goals beyond immediate narrow goals (Flum and Kaplan 2006), there is a need to examine the relations of motivational constructs (i.e., psychological factors) to short-term and long-term outcomes when considered together. This paper studies the relative contribution of each of four motivational factors (mastery goal, value of schooling, sense of competence, and affect to learning) in predicting four different educational outcomes. The outcomes include short-term (student achievement and rule acceptance) and long-term ones (general efficacy and identity).

\section{Academic motivation factors}

Motivation is known to have profound effects on student behaviour and learning (McInerney, Yeung and McInerney 2001; Smith et al. 2002). Although numerous studies have examined the significant influences of motivational factors on learning, the influence of each factor relative to other factors on various short-term and long-term educational outcomes needs further research. Amongst a wide range of motivational factors, four important and well documented ones are considered here.

Mastery goal orientation

Mastery goals focus on acquiring new learning and mastering skills. Research has suggested that mastery goal orientation is an adaptive motivational factor and has positive effects on learning (Martin 2007; Yeung and McInerney 2005). This orientation has been found to be related to positive outcomes, such as high performance (Elliot and Church 1997), and better perseverance with difficult tasks (Ryan and Pintrich 1998). Students with a mastery goal orientation are also able to maintain effort and interest in learning (Robins and Pals 2002). As mastery goals facilitate a focus on learning and task engagement, a promotion of mastery goals is likely to lead also to less disruptive student behaviour (Kaplan, Gheen and Midgley 2002). Thus this motivational factor has been of considerable interest to educators and researchers. Value of Schooling

Students' value of schooling relates to the extent to which students believe what they learn at school is relevant and meaningful (Martin 2007). Value of schooling is important in facilitating or inhibiting student motivation to achieve or continue schooling (McInerney, Dowson and Yeung 2005). This is in agreement with expectancy-value theory (Wigfield 1994) which argues that utility value is essential for students to achieve academically. Valuing of a learning task by a student leads to active engagement (Wigfield and Eccles 2000). Hence it is not surprising that students who value school work tend to achieve better because they engage themselves more in learning activities and work harder to improve. As such, value-related factors are strong predictors of long-term educational outcomes (e.g., career plans) (Jones et al. 2010).

\section{Competence}

The term "competence” here refers to the individual's self-perceived competence. A student's sense of competence may be conceptualized as the cognitive component of self-concept (i.e., how good a student in learning), which can be separated from the affective component (i.e., how much a student likes to learn) (Arens et al. 2011). Marsh and colleagues have demonstrated the causal relations between this cognitive component of academic self-concept and achievement outcomes (e.g., Marsh and Scalas 2010). Student's sense of competence often reflects their expectancy of success in learning (Wigfield and Eccles 2000). As students grow up, their perceptions of competence in school work tend to be more domain specific (Marsh, Craven and Debus 1999) and children begin to distinguish competence beliefs in 
different subject domains starting from the early years of schooling (Harter 1982). Children who have high competence beliefs have higher expectancies for success (Wigfield 1994) although their competence-related beliefs may decline as they grow older (Jacobs et al. 2002). Seifert (2004) advocates that for students to develop into healthy, adaptive, and constructive individuals, it is imperative to foster feelings of competence and control. Treating competence as an essential component of academic self-concept, Marsh and Craven (2006) have emphasized the mutual causal relations between this cognitive component of academic selfconcept and achievement outcomes.

Affect

The extent to which students like learning can be taken as the affective component of selfconcept (Arens et al. 2011; Marsh, Craven and Debus 1999). Students' positive affect towards learning involves interest in the learning tasks and a positive attitude toward learning activities. Students who have a strong positive affect are willing to continue investing time and effort in learning (Ryan and Deci 2000). Affect in relation to enjoying learning is therefore important for student engagement in educational settings. A positive affect tends not only to drive students to be more persistent, try harder, and have higher levels of motivation, it also seems to positively influence the cognitive processes underlying motivation resulting in better performance (Erez and Isen 2002). Yeung (2005) also argues that students' interest and engagement in school work may have important long-term benefits to students of all ages whereas their sense of competence may have more immediate effects.

\section{Educational outcomes}

Students have short-term and long-term needs. Personally valued long-term goals influence short-term self-regulation, which, through its impact on the achievement of short-term subgoals, leads in turn to future goal attainment (Miller and Brickman 2004). Students in a school setting may have different levels of motivation in meeting these goals, which may be short-term or long-term. Four educational outcomes are our focus: achievement and rule acceptance in the short-term, and identity and self-efficacy in the long-term, which are discussed below.

\section{Achievement}

Achievement scores have always been considered as one of the most important outcome variables in educational settings. Research has shown that students' motivation and selfconcept have significant influence on achievement scores (McInerney, Yeung and McInerney 2001). For example, Hammouri (2004) reported in his study on mathematics that motivational variables tended to have strong effects on achievement. Academic achievement and academic self-concept, being reciprocally related, are mutually reinforcing reinforcing (see Marsh and Craven 2006; Marsh, Byrne and Yeung 1999). That is, an increase in academic self-concept leads to an increase in academic achievement and vice versa (Marsh and Scalas 2010). Nevertheless, when self-concept is considered from a twofold multidimensional perspective with the competence and affect components treated as separate factors (Arens et al. 2011), we may envisage that a student's sense of competence would have considerable influence on immediate outcomes such as achievement, whereas affect would have considerable influence on longer-term outcomes (Yeung 2005). The influences of mastery goal and value of schooling on academic achievement may not be as clear. In particular, students who hold a strong mastery goal orientation tend to focus on the learning task and may not care whether they perform well in assessments. As such, although we would anticipate a positive relation between mastery goal and achievement, the positive influence of mastery goal on achievement may not be as strong as other predictors (value, competence, and affect).

Rule Acceptance 
Rule acceptance is primarily students' compliance with school rules, and is opposite to rule breaking. Rule breaking may be defined as the "failure to conform to the applicable normative expectations of the group” (Kaplan 1980, p. 5). In contrast, rule acceptance is the ability to conform to the expected norms of the school. School rules are intended to regulate student behaviour to make conditions conducive to learning for students. Students' perceptions of clarity of school rules are found to be significantly related to engagement and academic achievement (Brand et al. 2003). Breaking school rules leads to discipline sanctions resulting in suspensions and exclusion from school which may damage the learning process in many ways. Students who are punished and suspended for not conforming to the rules may be less bonded to the school, less interested in school work, and are subsequently less likely to achieve academic success (Gregory et al. 2010). Rule acceptance is therefore important in school contexts and is an important outcome in the short-term (i.e., the immediate environment within school life). However, how motivational factors such as mastery, value, competence, and affect may influence rule acceptance has never been systematically assessed. We may speculate that if students like and value school, they will be more willing to accept school rules and conform to them.

Self-efficacy

In contrast to domain-specific efficacy beliefs (Bandura 1994) or domain-specific competence beliefs (e.g., math self-concept, physical self-concept), general self-efficacy in the current study refers to one's confidence to solve problems and cope with life changes (Schwarzer and Born 1997). It is therefore a long-term educational outcome that is important for the lifelong wellbeing of an individual. However, the relations of general selfefficacy with the four predictors considered here have not been systematically explored. We may speculate that a strong sense of competence and mastery of knowledge would lead to stronger general self-efficacy, but the existing literature is currently unclear in relation to definitive directions.

Identity

Identity may be defined as a cohesive set of personal values regarding attitudes and life goals (Erickson 1968). Broadly, personal identity distinguishes individuals as a unique person whereas social identity emphasizes shared attributes among individuals. Identity formation begins from early childhood and persists through later years as an individual negotiates with experiences gathered in new contexts of life. It is this negotiation process that provides an individual with a sense of self-knowledge (Chatman, Eccles and Malanchuk 2005). One's selfrelated beliefs regarding one's relative competence and relative subjective task values form important sources of motivational contribution to identity development (Eccles 2009). For example, McCaslin (2009) argues that an individual's identity is formed through the participation in common activities in varying socio-cultural contexts. For students, school is the major socio-cultural context they engage in and therefore their motivation in school is likely to have considerable influences on their identity. Hence even when asked about their identity as a general sense of self, students' responses to an instrument about their identity is likely to reflect their sense of self in a school context (Marsh and Yeung 1999). Nevertheless, the relative influences of the four predictors on students' identity in a school setting are unclear and there is a paucity of research in this respect for us to formulate any hypothesis.

\section{The present investigation}

We surveyed a sample of primary school students in Australia and examined their motivation and self-concept and tested their relative influences on different learning outcomes, short- and long-term. We attempted to answer the research question: What is the relative strength of each of the four predictors in predicting the two short-term and two long-term educational outcomes? Based on previous empirical findings, two hypotheses were proposed: 
Hypothesis 1: Relative to other predictors, mastery goal would be stronger in predicting long-term goals whereas a sense of competence would be stronger in predicting short-term outcomes.

Hypothesis 2: Each of the four predictors would display a different pattern of predictions for the short-term and long-term outcomes.

\section{Method}

\section{Participants}

Students from six public primary schools funded by the State Government participated in this study $(N=979)$. The students came from grades 3, 4, 5, and 6 ( $n s=285,259,224$, and 211, respectively). The ages of the participants varied from 8 to 13 years $(M=9.78)$. Participants had low socio-economic status in comparison to other areas of Sydney, Australia and were comprised of diverse cultural groups (Yeung 2011).

\section{Materials}

Participants were asked to respond to a survey. Background variables included age, gender, ethnicity, and language background. The survey comprised of 35 items with four to seven items measuring each of seven factors (mastery, value, competence, affect, rule acceptance, identity, and efficacy). The students responded to the survey items in a random order on a 5point scale ( 1 =false to $5=$ true).

\section{Mastery}

Mastery was measured by six items adapted from Marsh et al. (2003) mastery goal scale with minor changes in wording to suit the reading ability of the sample. An example is: "I feel most successful in school when I reach personal goals".

Value of Schooling

This was adapted from Martin's (2007) Student Motivation and Engagement Scale with minor adjustments in wording. An example is: "What I learn at school will be useful one day".

\section{Competence}

Sense of competence was measured by Marsh’s (1993) Academic Self-Description Questionnaire II. An example is: "I am good at all school subjects”.

Affect

This was adapted from Marsh’s (1993) Academic Self-Description Questionnaire II with minor adjustment in wording. An example is: "I am interested in all school subjects".

Rule Acceptance

This was adapted from Parada's (2006) School Belonging Scale with minor adjustments. An example is: "I accept the rules of my school".

\section{Identity}

This was measured by Linnakyla (1996) Quality of School Life Scale. An example is: "I learn to get along with other people”.

Self-efficacy

Self-efficacy was measured by Schwarzer and Jerusalem’s (1995) General Self-Efficacy Scale. An example is: "I can always manage to solve difficult problems if I try hard enough".

Students completed a reading and numeracy achievement test for mid primary ( $3^{\text {rd }}$ and $4^{\text {th }}$ grades) or upper primary students $\left(5^{\text {th }}\right.$ and $6^{\text {th }}$ grades). The reading and numeracy tests required students to answer 20 multiple-choice questions for reading and numeracy each for mid primary students and 24 each for upper primary students. Each correct answer was scored as one, incorrect as zero.

\section{Procedure}

Procedures approved by the university's ethics committee were followed. The survey was administered in groups by a research assistant, and in some schools the class teacher also assisted to ensure students who needed help would be supported. 


\section{Statistical Analyses}

The students' responses to the survey items were coded such that higher scores reflected more favorable responses. In preliminary analysis, we examined the Cronbach's alpha estimate of internal consistency of each a priori scale. Then we conducted confirmatory factor analysis (CFA) and structural equation modelling (SEM) with the statistical package of Mplus, Version 6.0 (Muthén and Muthén 1998-2010). CFA is strong in representing theoretical factors (i.e., latent psychological constructs) derived from measured variables (i.e., responses to items). SEM has the advantage of testing causal relations between multiple predictors and multiple outcome variables, which is not possible with multiple regression procedures that can only handle one outcome at a time. Both CFA and SEM have the additional advantage of taking into account measurement errors for the items, hence more accurate in terms of measurement.

The procedures for conducting CFA and SEM have been described elsewhere (e.g., Byrne 1998; Jöreskog and Sörbom 2005) and are not further detailed here. The goodness of fit of the CFA models was evaluated with an emphasis on the Tucker-Lewis index (TLI, also known as the non-normed fit index) as the primary goodness-of-fit index. However, the chisquare test statistic and root mean square error of approximation (RMSEA) and the comparative fit index (CFI), are also reported. The goodness-of-fit statistics help us to understand how well a tested model actually reflects the data and how "close" the values are to the expected values. In general, the values of TLI and CFI should be equal to or greater than .90 for an acceptable fit and .95 for an excellent fit to the data. For RMSEA, according to Browne and Cudeck (1993), a value of .05 indicates a close fit, values near .08 indicate a fair fit, and values above .10 indicate a poor fit. Based on commonly accepted criteria (see Browne and Cudeck 1993; Jöreskog and Sörbom 2005), support for an acceptable model requires (a) acceptable reliability for each scale (i.e., alpha=.70 or above), (b) an acceptable model fit (i.e., TLI and RNI=.90 or above and RMSEA $<.08$ ), (c) acceptable factor loadings for the items loading on the respective factors (>.30), and (d) acceptable correlations among the latent factors such that they would be distinguishable from each other $(r<.90)$.

\section{Results}

\section{Confirmatory factor analysis (CFA)}

The alpha reliability of each scale was acceptable ( $\alpha$ s>.89, .75, .80, .89, .84, .82, .84, and .81 for Mastery, Value, Competence, Affect, Rule, Identity, Self-efficacy, and Achievement). Four sets of CFA models were tested and all resulted in proper solutions with acceptable fit (Table 1). The measurement models (Models 1 to 3 ) tested the integrity of the factors. Model 1a tested the four predictors (TLI=.951, CFI=.958, RMSEA=.051). Because a high correlation was found between Mastery and Value $(r=.88)$, the multicollinearity between these two factors could lead to misinterpretations of the paths from predictors to outcomes in later SEM (Marsh et al. 2004). Hence Model 1b was tested with Mastery and Value as a single factor (TLI=.940, $\mathrm{CFI}=.947$, RMSEA=.057) and the four-factor (1a) and three-factor (1b) models were compared. As Model 1a is clearly a better fitting model (see Chen, 2007), the four-factor model formed the basis for subsequent SEM. Model 2a tested three outcomes (rule, selfefficacy, and identity) (TLI=.948, CFI =.957, RMSEA=.056). Because a high correlation was found between self-efficacy and identity $(r=.84)$, Model 2b with self-efficacy and identity as one factor was tested (TLI=.913, CFI =.926, RMSEA=.073). Model 2a was found to be fitting better than Model 2b, and therefore three outcomes were used in subsequent SEM. Model 3 included the four predictors and all four outcomes, including achievement (TLI=.933, $\mathrm{CFI}=.940$, RMSEA=.044). Based on the established factors in Model 3, we were able to test the relative influences of the four predictors on the four outcomes in a path model. Model 4 is an SEM model testing the paths from the four predictors to the four outcomes. As Model 4 is equivalent to Model 3, they displayed the same model fit (Table 1). Table 2 presents the factor 
loadings and correlations of Model 3. As can be seen in Table 2, the factor loadings were acceptable (all $>.50$ ). The factor correlations ranged from .17 to .88. The highest correlation was between the Value and Mastery factors, which was logical although the correlation was high $(r=.88)$. Overall, the eight factors were well defined and were distinct from each other. The four predictors were positively correlated with all four outcomes ( $r$ s ranging from .20 to .80, all $p s<.05$ ), indicating that they had positive relations to each other.

\section{Path model}

\section{Insert Tables 1 and 2 About Here}

The paths from the four predictors to the four outcome measures are presented in Figure 1. From Mastery, the paths to Self-efficacy $(\beta=.48, S E=.09)$ and Identity $(\beta=.42, S E=.09)$ were both positive and statistically significant $(p<.05)$, but the paths to Achievement and Rule Acceptance were not. For Value, three paths were positive and statistically significant to Achievement $(\beta=.39, S E=.13)$, Rule Acceptance $(\beta=.54, S E=.10)$, and Identity $(\beta=.27$, $S E=.09)$, but not for Self-efficacy. For Competence, the paths to Achievement $(\beta=.43, S E=.08)$ and Self-efficacy $(\beta=.46, S E=.05)$ were positive and statistically significant, but not the other two paths. For Affect, the paths to Rule Acceptance $(\beta=.17, S E=.06)$ and Identity $(\beta=.19$, $S E=.06)$ were positive and statistically significant but interestingly the path to Achievement $(\beta=-.29, S E=.08)$ was negative even though the correlation between Affect and Achievement was positive $(r=.20)$.

\section{Discussion}

The results showed statistically significant correlations between the four motivation factors and the four outcome factors (all $r$ s were positive and statistically significant), demonstrating that all the motivational factors were positively related to both the short-term and long-term educational outcomes when considered separately. The purpose of the path model (Figure 1) was to provide a more stringent explication of the relative strength of each predictor in predicting each outcome variable. The advantage of using this structural equation modelling approach is to be able to answer the research question of which predictor best predicts which outcome when there are multiple predictors and multiple outcomes to be tested simultaneously. Other than the Affect to Achievement path which was negative and statistically significant, all the statistically significant paths were positive (Figure 1).

Mastery was found to have relatively strong influences on both Efficacy $(\beta=.48, S E=.09$ ) and Identity $(\beta=.42, S E=.09)$. These results suggest that students with a mastery orientation may have higher self-efficacy beliefs. It also seems that students who hold a mastery orientation may develop a healthy identity. Hence mastery goals are a good predictor of these important long-term outcomes. In essence, mastery goals have important influences on successful living for any individual. Future research should therefore attempt to investigate how this motivational factor may be related to other long-term goals such as optimism and psychological wellbeing.

Value of schooling was found to have strong influences on Achievement, Rule Acceptance, and Identity but there seemed to be a stronger positive association with rule acceptance $(\beta=.54, S E=.10)$, than with achievement $(\beta=.39, S E=.13)$ and identity $(\beta=.27$, $S E=.09)$. This result suggests that students who value schooling may agree with the enforcement of school rules and are more willing to conform to these rules in school. Moreover, students who value school also have the benefit of striving for better achievement and forming a desirable identity (Figure 1). This means that Value of Schooling not only predicts achievement but is also a significant predictor of other short-term gains such as Rule Acceptance and long-term gains such as students' Identity. Therefore, educators may find it useful to implement strategies to maintain and develop students' Value of Schooling through primary school years. 
Competence had a relatively strong influence on both Achievement $(\beta=.43, S E=.08)$ and Efficacy $(\beta=.46, S E=.05)$. The association with Achievement is consistent with previous research which has demonstrated the causal relations between this cognitive component of academic self-concept and achievement (e.g., Marsh and Craven 2006; Marsh, Byrne and Yeung 1999) and the importance of a sense of competence in predicting academic performance (Pajares and Schunk 2002). Further to these findings, our data also showed that students' sense of competence may also foster self-efficacy. Apparently, this result supports Miller and Brickman's (2004) argument that future goals are related to a system of short-term subgoals. Nevertheless, how the short-term and long-term goals share a relation and develop simultaneously requires further research.

Affect was found to have negative influences on Achievement $(\beta=-.29, S E=.08)$ and a positive influence on Rule Acceptance $(\beta=.17, S E=.06)$ and Identity $(\beta=.19, S E=.06)$. The results suggest that students who enjoy school may be willing to conform to the rules of the school and may develop a healthy identity but may not achieve well academically. The result also implies that affect tends to be the weakest predictor of achievement among all other predictors. However, this interpretation needs further research to clarify the underlying processes for students' formulation of affect in schooling contexts.

\section{Limitations}

It is important to note some of the limitations in this study which need to be accounted for in interpreting the findings. Students sampled in this study were limited to six public schools in Australia and were not fully representative of all students in the Australian school system. The current research needs to be extended to a larger sample of students from different school types and regions. Research should also be conducted in other school settings in other countries for generalisation of the patterns found with the current sample.

Also, because this study was based on cross-sectional data, we were unable to test the reciprocal effects between variables. Even though we might expect reciprocal relations between an individual's sense of competence and academic achievement to be mutually influencing each other (Marsh, Byrne and Yeung 1999), such effects cannot be tested without longitudinal data. In fact, we believe that some of the relations depicted in our model (e.g., predictors and outcomes) could be opposite in direction or reciprocal in nature. Hence the causal ordering of these variables should be explored in future research using longitudinal data. This way, we will be able to test the reciprocal relations of variables controlling for their prior effects between time points. Future studies would also benefit from the change of these variables and their relations over time by undertaking a more nuanced analysis of developmental patterns. This will enable us to clearly justify the terms of "short-term" and "long-term" outcomes by establishing temporal relations between variables in a longitudinal design.

Methodologically, despite the strength of CFA and SEM, potential multicollinearity problems can lead to misinterpretation of predictions (Marsh et al. 2004). The establishment of the various factors distinct from each other and the reasonably low standard errors related to the estimates indicate that this problem is unlikely for our sample here. However, we should take caution in interpreting the findings. Finally, there is also a need for research aiming to advance the understanding of the complexities of personality and context in relation to motivation and how they may impact on the prediction of educational outcomes. These have mostly been neglected and may have important practical implications for addressing individual differences.

\section{Conclusion}

Our results show that Mastery is a significant predictor of Efficacy and Identity, Value of Schooling is a significant predictor of Rule Acceptance and Achievement, students' sense of 
competence is a predictor of Achievement and Efficacy whereas Affect is a negative predictor of Achievement but a positive predictor of Identity. In sum, mastery goals predict long-term gains, which is in sharp contrast to Value of Schooling which predicts short-term gains better. Competence is a good predictor of both long- and short-term gains whereas Affect may help develop long-term outcomes such as Identity. Educators would benefit students by enhancing all four motivational factors so that students can enjoy both short-term and long-term benefits of education. 


\section{References}

Arens, A.K., A.S. Yeung, R.G. Craven, and M. Hasselhorn. 2011. The twofold multidimensionality of academic self-concept: Domain specificity and separation between competence and affect components. Journal of Educational Psychology 103, no. 4: 970-981.

Bandura. A. 1994. Self-efficacy. In Encyclopedia of Human Behaviour, ed. V. S. Ramachaudran (vol. 4), 71-81. New York: Academic Press.

Brand, S., R. Felner, M. Shim, A. Seitsinger, and T. Dumas. 2003. Middle school improvement and reform: Development and validation of a school-level assessment of climate, cultural pluralism, and school safety. Journal of Educational Psychology 95, no. 3: 570-588.

Browne, M.W., and T. Cudeck. 1993. Alternative ways of assessing model fit. In Testing Structural Equation Models, ed. K. A. Bollen and J. S. Long, 136-162. Newbury Park CA: Sage.

Byrne, B.M. 1998. Structural equation modeling with LISREL, PRELIS, and SIMPLIS: Basic concepts, applications, and programming. Mahwah, NJ: Erlbaum.

Chatman, C.M., J.S. Eccles, and O. Malanchuk. 2005. Identity negotiation in everyday settings. In Navigating the Future: Social identity, Coping and Life Tasks, ed. G. Downey, J.S. Eccles, and C.M. Chatman, 116-139. New York: Russell Sage Foundation.

Craven, R.G., and A.S. Yeung. 2008. International best practice in effective educational interventions: Why self-concept matters and examples from bullying, peer support, and reading research. In Research on Sociocultural Influences on Motivation and Learning. Vol. 8: Teaching and learning: International best practice, ed. D. M. McInerney, V. E. Shawn, and M. Dowson, 267-294. Greenwich, CT: Information Age.

Eccles, J.S. 2009. Who am I and what am I going to do with my life? Personal and collective identities as motivators of action. Educational Psychologist 44, no. 2: 78-89.

Elliot, A., and M. Church. 1997. A hierarchical model of approach and avoidance achievement motivation. Journal of Personality and Social Psychology 72, no. 1: 218232.

Erez, A., and A.M. Isen. 2002. The influence of positive affect on the components of expectancy motivation. Journal of Applied Psychology 87, no. 6: 1055-1067.

Erickson, E.H. 1968. Identity: Youth and Crisis (London, Faber \& Faber).

Flum, H., and A. Kaplan. 2006. Exploratory orientation as an educational goal. Educational Psychologist 41, no. 2: 99-110.

Gregory, A., Skiba, R. J. and Noguera, P. A. 2010. The achievement gap and the discipline gap: Two sides of the same coin? Educational Researcher 39, 59-68.

Hammouri, H.A.M. 2004. Attitudinal and motivational variables related to mathematics achievement in Jordan: findings from the Third International Mathematics and Science Study (TIMSS). Educational Research 46, no. 3: 241-257.

Harter, S. 1982. The perceived competence scale for children. Child Development 53, 87-97. Jacobs, J. E., S. Lanza, D.W. Wayne Osgood, J.S. Eccles, and A. Wigfield. 2002. Changes in children's self-competence and values: Gender and domain differences across grades one through twelve. Child Development 73, no. 2: 509-527.

Jones, B.D., M.C. Paretti, S.F. Hein, and T.W. Knot. 2010. An analysis of motivation constructs with first-year engineering students: relationships among expectancies, values, achievement, and career plans. Journal of Engineering Education 99, no. 4: 319-336. 
Jöreskog, K.G., and D. Sörbom. 2005. LISREL 8.72: Structural Equation Modeling with SIMPLIS command language. Chicago: Scientific Software International.

Kaplan, H.B. 1980. Deviant Behavior in Defense of Self (New York, Academic Press).

Kaplan, A., M. Gheen, and C. Midgley. 2002. The classroom goal structure and student disruptive behavior. British Journal of Educational Psychology 72, no. 2: 191-211.

Linnakyla, P. 1996. Quality of school life in the Finnish comprehensive school: A comparative view. Scandinavian Journal of Educational Research 40, 69- 85.

Marsh, H.W. 1993. The multidimensional structure of academic self-concept: Invariance over gender and age. American Educational Research Journal 30, no. 4: 841-860.

Marsh, H.W., B.M. Byrne, and A.S. Yeung 1999). Causal ordering of academic self-concept and achievement: Reanalysis of a pioneering study and revised recommendations. Educational Psychologist 34, no. 3: 155-167.

Marsh, H.W., and R.G. Craven. 2006. Reciprocal effects of self-concept and performance from a multidimensional perspective: Beyond seductive pleasure and unidimensional perspectives. Perspectives on Psychological Science 1, no. 2: 133-163.

Marsh, H.W., R. Craven, and R. Debus. 1999. Separation of competency and affect components of multiple dimensions of academic self-concept: A developmental perspective. Merrill-Palmer Quarterly 45: 567-601.

Marsh, H.W., M. Dowson, J. Pietsch, and R. Walker. 2004. Why multicollinearity matters: a Reexamination of relations between self-efficacy, self-concept, and achievement. Journal of Educational Psychology 96, no. 3: 518-522.

Marsh, H.W., and L.F. Scalas. 2010. Self-concept and learning: Reciprocal effects model between academic self-concept and academic achievement. In International Encyclopedia of Education, ed. B. McGaw, E. Baker, P. P. Peterson. New York: Elsevier.

Marsh, H.W., and A.S. Yeung. 1999. The lability of psychological ratings: The chameleon effect in global self-esteem. Personality and Social Psychology Bulletin 25, no. 1: 4964.

Martin, A.J. 2007. Examining a multidimensional model of student motivation and engagement using a construct validation approach. British Journal of Educational Psychology 77, no. 2: 413-440.

McCaslin, M. 2009. Co-regulation of student motivation and emergent identity. Educational Psychologist 44, no. 2: 137-146.

McInerney, D.M., M. Dowson, and A.S. Yeung. 2005. Facilitating conditions for school motivation: Construct validity and applicability. Educational and Psychological Measurement 65, no. 6: 1046-1066.

McInerney, D.M., A.S. Yeung, and V. McInerney. 2001. Cross-cultural validation of the Inventory of School Motivation (ISM): Motivation orientations of Navajo and Anglo students. Journal of Applied Measurement 2, 135-153.

Miller, R.B., and S.J. Brickman. 2004. A model of future-oriented motivation and selfregulation. Educational Psychology Review 16, no. 1: 9-33.

Muthén, L.K., and B.O. Muthén. 1998 -2010. Mplus User's Guide ( $5^{\text {th }}$ ed.) (Los Angeles, CA, Muthén and Muthén).

Pajares, F., and D.H. Schunk. 2002. Self and self-belief in psychology and education: a historical perspective. In Improving Academic Achievement: Impact of Psychological Factors on Education, ed. J. Aronson, 3-21. San Diego, CA: Academic Press.

Parada, R.H. 2006. School bullying: Psychosocial determinants and effective intervention. Unpublished Ph.D thesis, University of Western Sydney. 
Robins, R.W., and J.L. Pals. 2002. Implicit self-theories in the academic domain: Implications for goal orientation, attributions, affect, and self-esteem change. Self and Identity 1, no. 4: 313-336.

Ryan, R., and E. Deci. 2000. Self-determination theory and the facilitation of intrinsic motivation, social development, and well-being. American Psychologist 55, no. 1: 68-78.

Ryan, A.M., and P.R. Pintrich. 1998. Achievement and social motivational influences on help seeking in the classroom. In Strategic Help Seeking: Implications for Learning and Teaching, ed. S.A. Karabenick, 117-139. Mahwah, NJ: Erlbaum.

Schwarzer, R., and A. Born. 1997. Optimistic self-beliefs: assessment of general perceived self-efficacy in thirteen cultures. World Psychology 3, no. 1-2: 177-190.

Schwarzer, R., and M. Jerusalem. 1995. Generalized Self-Efficacy scale. In Measures in Health Psychology: A user's portfolio. Causal and Control Beliefs, ed. J. Weinman, S. Wright, and M. Johnston, 35-37. Windsor, UK: NFER-Nelson.

Seifert, T.L. 2004. Understanding student motivation. Educational Research 46, no. 2: 137149.

Smith, M., J. Duda, J. Allen, and H. Hall. 2002. Contemporary measures of approach and avoidance orientations: Similarities and differences. British Journal of Educational Psychology 72, no. 2: 155-190.

Wigfield, A. 1994. Expectancy-value theory of achievement motivation: A developmental perspective. Educational Psychology Review 6, no. 1: 49-78.

Wigfield, A., and J. S. Eccles. 2000. Expectancy-value theory of achievement motivation. Contemporary Educational Psychology 25, no. 1: 68-81.

Yeung, A.S. 2005. Reconsidering the measurement of student self-concept: Use and misuse in a Chinese context. In The New Frontiers of Self Research, ed. H.W. Marsh, 233-257. Sydney: Information Age.

Yeung, A.S. 2011. Student self-concept and effort: Gender and grade differences. Educational Psychology 31, no. 6: 749-772.

Yeung, A.S. and D.M. McInerney. 2005. Students' school motivation and aspiration over high school years. Educational Psychology 25, no. 5: 537-554. 
Table 1: Goodness-of-fit

\begin{tabular}{lcccccc} 
Model & $\chi^{2}$ & $\underline{\text { Items }}$ & $\underline{d f}$ & $\underline{\text { TLI }}$ & $\underline{\text { CFI }}$ & RMSEA \\
1. 4 predictors $(p)$ & 585.26 & 20 & 164 & .95 & .96 & .05 \\
2. 3 outcomes $(0)$ & 356.50 & 15 & 87 & .95 & .96 & .06 \\
3. $8(p+$ +o+Ach $)$ & 1725.10 & 37 & 601 & .93 & .94 & .04 \\
4. Path Model & 1725.10 & 37 & 601 & .93 & .94 & .04 \\
\hline
\end{tabular}

Note: $N=979$. CFI=Comparative Fit index. TLI=Tucker-Lewis index. RMSEA=Root mean square error of approximation. Ach=Achievement. 
TABLE 2: Model 4

\begin{tabular}{|c|c|c|c|c|c|c|c|c|c|}
\hline Variable $\mathrm{Ma}$ & tery & Value & Competence & Affect & Ach & Rule E & Efficacy & Identity & Unique \\
\hline$\overline{\text { Mean }}$ & .43 & 4.47 & 3.86 & 3.74 & 72.06 & 4.36 & 3.95 & 4.13 & \\
\hline SD & .74 & 0.70 & 0.77 & 1.06 & 18.85 & 0.86 & 0.78 & 0.85 & \\
\hline Factor Load & $n g s$ & & & & & & & & \\
\hline Mastery1 & $.72 *$ & & & & & & & & $.49 *$ \\
\hline Mastery2 & $.78^{*}$ & & & & & & & & $.40 *$ \\
\hline Mastery3 & $.76^{\star}$ & & & & & & & & $.42^{*}$ \\
\hline Mastery4 & $.74^{\star}$ & & & & & & & & $.43^{\star}$ \\
\hline Mastery5 & $.75 *$ & & & & & & & & $.43^{*}$ \\
\hline Mastery6 & $.78^{\star}$ & & & & & & & & $.39 *$ \\
\hline Value1 & & $.65^{\star}$ & & & & & & & $.58 *$ \\
\hline Value2 & & $.69 *$ & & & & & & & $.52 *$ \\
\hline Value3 & & $.54 *$ & & & & & & & $.71^{\star}$ \\
\hline Value4 & & $.74 *$ & & & & & & & $.45^{\star}$ \\
\hline Compet1 & & & $.64 *$ & & & & & & $.60 *$ \\
\hline Compet 2 & & & $.72 *$ & & & & & & $.48 *$ \\
\hline Compet3 & & & $.70 *$ & & & & & & $.51 *$ \\
\hline Compet 4 & & & $.48^{*}$ & & & & & & $.77^{*}$ \\
\hline Compet5 & & & $.81^{\star}$ & & & & & & $.35 *$ \\
\hline Affect 1 & & & & $.80 *$ & & & & & $.36 *$ \\
\hline Affect 2 & & & & $.55 *$ & & & & & $.70 *$ \\
\hline Affect 3 & & & & $.84 *$ & & & & & $.30 *$ \\
\hline Affect 4 & & & & $.85 *$ & & & & & $.28 *$ \\
\hline Affect5 & & & & $.87 *$ & & & & & .25 * \\
\hline readpc & & & & & $.80 *$ & & & & $.37 *$ \\
\hline numpc & & & & & $.86 *$ & & & & $.53^{*}$ \\
\hline Rule1 & & & & & & $.79 *$ & & & $.37 *$ \\
\hline Rule2 & & & & & & $.69 *$ & & & $.53 *$ \\
\hline Rule3 & & & & & & $.79 *$ & & & $.37 *$ \\
\hline Rule4 & & & & & & $.72 *$ & & & $.48 *$ \\
\hline Efficacy 1 & & & & & & & $.72 *$ & & $.47^{\star}$ \\
\hline Efficacy 2 & & & & & & & $.68 *$ & & $.54 *$ \\
\hline Efficacy3 & & & & & & & $.75^{\star}$ & & $.45^{\star}$ \\
\hline Efficacy4 & & & & & & & $.75^{\star}$ & & $.45^{*}$ \\
\hline Efficacy 5 & & & & & & & $.55^{*}$ & & $.69 *$ \\
\hline Efficacy 6 & & & & & & & $.66^{*}$ & & $.56 *$ \\
\hline Identity1 & & & & & & & & $.67 *$ & $.55^{*}$ \\
\hline Identity2 & & & & & & & & $.72^{\star}$ & $.48 *$ \\
\hline Identity3 & & & & & & & & $.72^{*}$ & $.48^{*}$ \\
\hline Identity4 & & & & & & & & $.71 *$ & $.49 *$ \\
\hline Identity5 & & & & & & & & $.62^{*}$ & $.61^{\star}$ \\
\hline Factor Corr & latic & ons & & & & & & & \\
\hline Value & $.88^{\star}$ & & & & & & & & \\
\hline Competence & $.59 *$ & $.51^{\star}$ & & & & & & & \\
\hline Affect & $.59 *$ & $.62 *$ & $.77^{\star}$ & & & & & & \\
\hline Achievement & $.30 *$ & $.32 *$ & $.33^{\star}$ & $.20 *$ & & & & & \\
\hline Rule & $.76^{\star}$ & $.80^{*}$ & $.51 *$ & $.61^{\star}$ & $.34 *$ & & & & \\
\hline Efficacy & $.77^{\star}$ & $.68 *$ & $.73^{*}$ & $.61^{*}$ & $.22^{*}$ & $.64 *$ & & & \\
\hline Identity & $.79 *$ & $.77^{*}$ & $.58 *$ & $.64^{\star}$ & $.17^{\star}$ & $.71^{\star}$ & $.84^{*}$ & & \\
\hline
\end{tabular}

Note: ${ }^{*} p<.05 . N=979$. Compet=Competence. Rule=Rule acceptance. Ach=Achievement.

Unique=Uniqueness. Parameter estimates are completely standardised. 


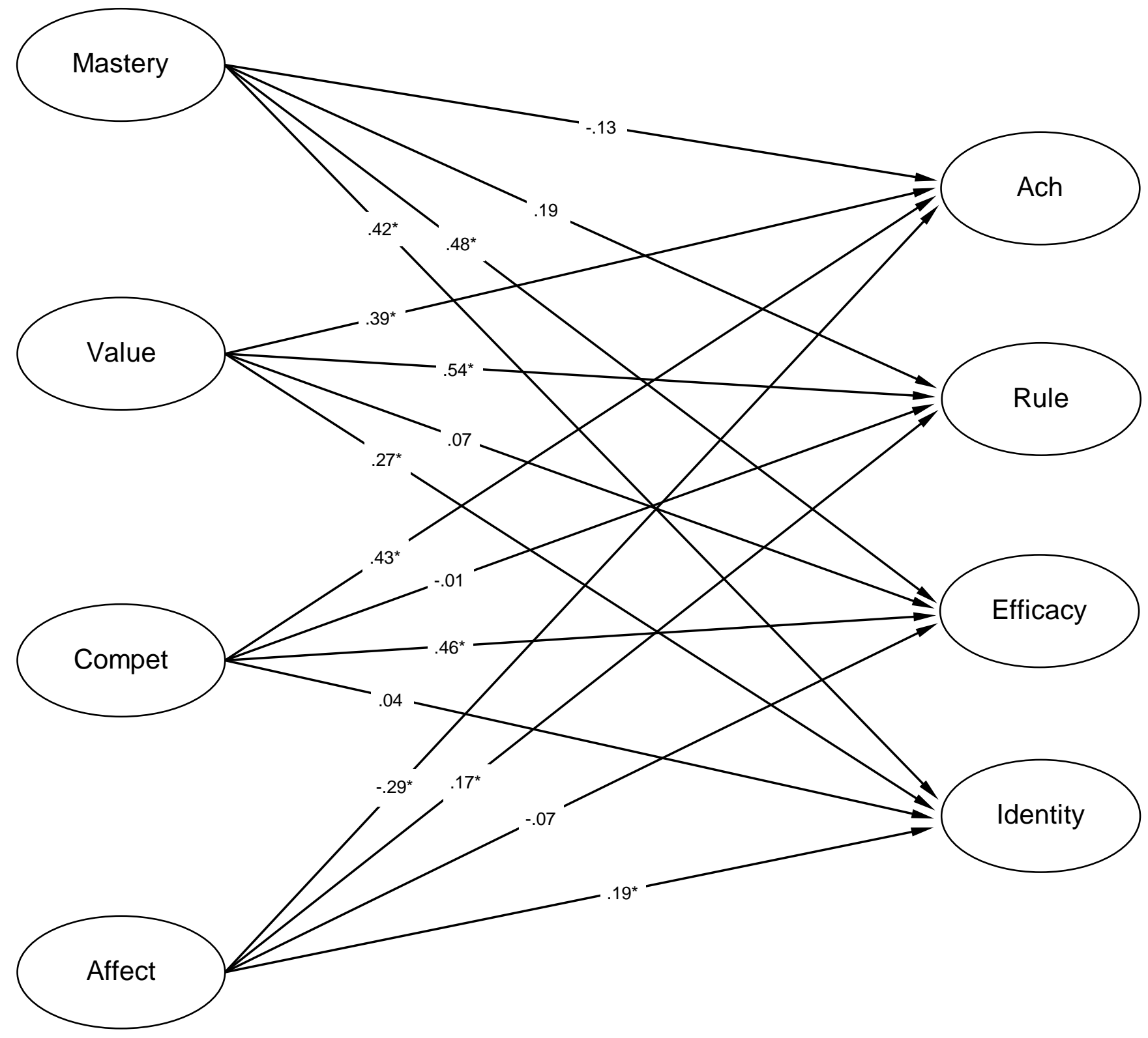

Figure 1. Structural equation model: Paths from 4 motivation variables to 4 outcomes Note: ${ }^{*} p<.05$. Compet=Sense of Competence. Ach=Achievement. The paths are (completely standardised). That is, the coefficients are standardised using the variance of both the predictor and outcome variables so that all paths are on the same metric to be directly comparable. 